\title{
Intravesical Electrical Stimulation for the Rehabilitation of the Neuropathic Bladder
}

\author{
H. Madersbacher \\ Department of Urology, University Hospital Innsbruck, Consultant Urologist, \\ Rehabilitation Center, Bad Haring, Tirol, Austria.
}

The idea of intravesical electrostimulation dates back to 1878 when the Danish surgeon M. H. Saxtorph treated urinary retention by inserting a special catheter transurethrally into the bladder with a metal-electrode inside and with a neutral electrode placed suprapubically. No further publication appeared dealing with this technique till 1959, when F. Katona et al., described their technique of intraluminal electrotherapy. This method was initially designed for the treatment of a paralytic gastrointestinal tract. Later on Katona (1975) used this method extensively for the treatment of neurogenic bladder dysfunction. Subsequently this technique was also applied by others with controversial results (Janneck, 1975; Nicholas and Eckstein, 1975; Farnsworth, 1976; Berger et al., 1978; Seiferth et al., 1978; Madersbacher, 1978; Madersbacher et al., 1982; Katona et al., 1984; Madersbacher, 1984; Madersbacher et al., 1987).

The basis for intravesical electrotherapy is the fact, that in patients with incomplete central or peripheral nerve lesions - and only these patients are suitable for this method-at least some nerve pathways between the bladder and the cerebral centers are preserved, but are too weak to be efficient under normal circumstances.

Transurethral electrostimulation (TES) of the bladder is based on the activation of the specific receptors in the bladder wall. Therefore this method follows some important principles of neurophysiology. Normally no movement begins without sensory reaction and no normal movement can proceed without feedback processes integrated in the control of movements (Granit, 1970). Adequate sensory inputthe generation of impulses in the receptors by intravesical pressure-is also the prerequisite for conscious bladder control. Absence of efferent impulses prevents receptor-depolarisation and makes them unexcitable.

The initial effect of TES is depolarisation of the receptors with activation of the intramural motor system, resulting in small local muscle contractions, which further depolarise the receptor-cells. As soon as this local motor reaction reaches a certain strength vegetative afferentation begins. This means that stimuli travel along afferent pathways to the corresponding cerebral structures. The clinicalsign of this afferentation is the occurrence of sensation. This in time reinforces efferent 
pathways. Their stimuli create centrally induced, more coordinated and stronger detrusor contractions. However, especially children with congenital neurogenic bladder dysfunction, who have never experienced the urge to void, require to learn to realise the nature and meaning of this new sensation, induced by TES. For this reason a second system must be introduced adding exteroceptive stimulation to TES.

The TES-technique involves direct intraluminal monopolar electrical stimulation via a special catheter equipped with a stimulation electrode, which is connected by a thin silver wire through the catheter to the stimulator. Sodium chloride is used as the current leading fluid medium in the bladder. Interesting enough, and confirming the local effect of TES on the receptors, the effect of intravesical electrostimulation can be abolished by intravesical instillation of Xylocaine.

Exteroceptive reinforcement is achieved by visual recording of the detrusor contractions on the standpipe of a water-manometer, connected to the stimulationcatheter. This exteroceptive stimulation is also important for spinal cord injury (SCI) patients during TES-therapy. It indicates to the patient detrusor contractions and whether and to what degree conscious control of the detrusor is or has become possible. By demonstrating progress this operative conditioning serves as a positive feedback for the patient. An intensive bladder training programme has to be combined with TES. This fact, often ignored, may explain some of the controversies concerning the effectiveness of the method. Control of therapy comprises continuous urodynamic monitoring during TES in order to adapt the stimulation parameters to the reaction of the detrusor. Each patient requires a highly individual stimulation programme, another fact, which also was ignored by some colleagues having used this method with disappointing results.

The underlying concept implies that only patients with incomplete spinal cord lesions, with receptors still capable to react and a detrusor still able to contract, will benefit from TES, moreover the achievement of conscious control deserves an intact cortex.

Since 1976 we have applied intravesical electrotherapy (1) in patients with incomplete spinal cord injuries, (2) in children and neonates with congenital neurogenic bladder dysfunction and (3) during the past 3 years also in patients with non-neurogenic dysfunctional voiding, especially in children.

A retrospective computer-analysis on the results in patients with SCI, recently published (Madersbacher et al., 1987) has lead us to conclude, that roughly in about one third of our patients the improvement in detrusor function (sensation, contractility and conscious control) has to be attributed to intravesical electrotherapy in the sense, that TES was responsible for the results. In others it may have at least facilitated bladder rehabilitation.

However, there would appear to be a number of arguments, which may cause doubt on there being a close relationship between this type of therapy and the results obtained. Neither we nor other authors are able to compare the results with an untreated control-group. But such a control-group would be difficult to establish. However, we have compared the improvement of detrusor function in SCI patients with the general recovery of motor and sensory function, e.g. in regard to detrusor contractility. In $38 \%$ of the patients the improvement of detrusor-contractility was much better than that of 'general neurological recovery' according to Frankel's scale; in $34 \%$ it correlated with the general recovery; in 
$26 \%$ a meaningful comparison was not possible. Furthermore, in $30 \%$ of the patients the achievement of conscious control of micturition was not accompanied by the same improvement of motor and sensory function; in another $20 \%$ it was the opposite; in $40 \%$ the achievement of conscious control and general recovery were well correlated; and in 10\% no comparison was possible.

It is interesting to note that only patients with preserved pain sensation in the sacral skin dermatomes S2-S4 improved with TES. This correlates well with the findings of Nathan and Smith (1958), who located the spinal pathways of micturition in the neighbourhood of the pain conducting spinothalamic tract.

Children with congenital neurogenic bladder dysfunction mostly benefit from this type of therapy (Katona, 1975; Madersbacher, 1984). So far no other technique has been available to induce bladder sensation and conscious micturition control in these children.

But the method also has disadvantages: there is no simple investigation of predictive value. So far the first 10-15 stimulations have to be regarded as a trial which should be continued once a positive response is registered, and performed until an optimal response is achieved. TES is timeconsuming; its performance needs an experienced nurse and adequate facilities to achieve the results. The duration of the initial therapy as well as the need for restimulation mainly depend on the underlying pathophysiology: in children with non-neurogenic dysfunctional voiding the mean number of stimulations is about 20 and the need for restimulation rare, whereas in patients with a neurogenic bladder dysfunction intermittent longterm therapy may be required.

The progress observed during intravesical electrotherapy and documented by urodynamics as well as the clinical follow-up studies definitely indicate that this type of therapy, although usually not spectacular immediately, is of remarkable benefit for bladder rehabilitation in patients with neurogenic detrusor dysfunction. Additional basic research should be performed to prove the underlying working concept and to further evaluate the optimal stimulation technique.

\section{References}

Berger D, BERgER K, GENTON W 1978 Endovesical transurethral electrostimulation in the rehabilitation of neurogenic bladder in children. European Urology 4:33-45.

FARNSWORTH RH 1976 Electrostimulation in the management of neurogenic bladder disorders. British Fournal of Urology 48:149-150.

GRANIT R 1970 The basis of motor control. Academic Press, London, New York, p 215.

JANNECK C 1975 Electric stimulation of the bladder and the anal sphincter. A new way to treat the neurogenic bladder. Progress in Paediatric Surgery 9:119-139.

KATONA F, BENYO L, LANG J 1959 Über intraluminäre Electrotherapie vor verschiedenen paralytischen Zuständen des gastrointestinalen Traktes mit Quadrangulärstrom. Zbl. Chir. 84:929-933.

KATONA F 1975 Stages of vegetative afferentation in reorganisation of bladder control during electrotherapy. Urologia Internationalis 30:192-203.

Katona F, Berenyi M, Szabados P, Balazs M, Tunyogi E, Vegh I 1984 Early electro-urodynamics and early intravesical electrotherapy. Proceedings, ICS, 1984 Plattner-Druck, Innsbruck, Austria, pp 35-38:

MADERSBACHER H 1978 Der Effekt der transurethralen Elektrostimulation auf die gelähmte und inkontinente Blase: objektive Ergebnisse. Urologe Ausgabe A 17:335-357.

MADERSBACHER H, PAUER W, RAINER E 1982 Rehabilitation of micturition by transurethral electrostimulation of the bladder in patients with incomplete spinal cord lesions. Paraplegia 20:191-195.

MADERSBACHER H 1984 Blasen(re)habilitation bei Kindern mit neurogener Harnentleerungsstörung mittels Biofeedback unter Verwendung der transurethralen Elektrostimulation. Akt. Urologie 15:248243. 
MAdersbacher H, Hetzel H, GotTinger F, EBNER A 1987 Rehabilitation of micturition in adults with incomplete spinal cord lesions by intravesical electrotherapy. Fournal Neurology and Urodynamics 6:230-232.

Nathan PW, SMITH MC 1958 Centripetal pathway from bladder and urethra fournal of Neurology, Neurosurgery and Psychiatry 21:177-189.

NiCOLAS JL, ECKSTEIN HB 1975 Endovesical electrotherapy in treatment of urinary incontinence in spina bifida patients. Lancet 1276-1277.

SAXTORPH MH 1878 Strictura urethrae-Fistula perinei-Retentio urinae. Clinisk Chirurgi, Gyldendalske Forlag, Copenhagen, pp 265-280.

SEIFERTH J, LARKAMP H, HEISING J 1978 Erfahrungen mit der temporären, intravesicalen Elektrostimulation bei neurogener Blasenentleerungsstörung von Spinabifida-Kindern. Urologe Ausgabe A 17:353-357. 